\title{
Synergistic Doping of Fullerene Electron Transport Layer and Colloidal Quantum Dot Solids Enhances Solar Cell Performance
}

\author{
Mingjian Yuan, Oleksandr Voznyy, David Zhitomirsky, \\ Pongsakorn Kanjanaboos, and Edward H. Sargent
}

Version Post-Print/Accepted Manuscript

Citation Yuan, M., Voznyy, O., Zhitomirsky, D., Kanjanaboos, P., \& Sargent, E. (published version) (2014). Synergistic Doping of Fullerene Electron Transport Layer and Colloidal Quantum Dot Solids Enhances Solar Cell Performance. Advanced Materials, 27(5), 917-921. http://dx.doi.org/10.1002/adma.201404411

Publisher's Statement This is the peer reviewed version of the following article: Yuan, M., Voznyy, O., Zhitomirsky, D., Kanjanaboos, P., \& Sargent, E. (2014). Synergistic Doping of Fullerene Electron Transport Layer and Colloidal Quantum Dot Solids Enhances Solar Cell Performance. Advanced Materials, 27(5), 917-921, which has been published in final form at http://dx.doi.org/10.1002/adma.201404411. This article may be used for non-commercial purposes in accordance with Wiley Terms and Conditions for Self-Archiving.

\section{How to cite TSpace items}

Always cite the published version, so the author(s) will receive recognition through services that track citation counts, e.g. Scopus. If you need to cite the page number of the TSpace version (original manuscript or accepted manuscript) because you cannot access the published version, then cite the TSpace version in addition to the published version using the permanent URI (handle) found on the record page. 
DOI: $10.1002 /(($ please add manuscript number $))$

Article type: Communication

Synergistic Doping of Fullerene Electron Transport Layer and Colloidal Quantum Dot Solids Enhances Solar Cell Performance

Mingjian Yuan, ${ }^{+}$Oleksandr Voznyy, ${ }^{+}$David Zhitomirsky, Pongsakorn Kanjanaboos, Edward H. Sargent*

[*] Prof. E. H. Sargent, Dr. M. Yuan, Dr. O. Voznyy, Dr. D. Zhitomirsky, Dr. P. Kanjanaboos

Department of Electrical and Computer Engineering, University of Toronto, 10 King's College Road, Toronto, Ontario, M5S 3G4, Canada E-mail: ted.sargent@utoronto.ca

Keywords: PbS, PCBM, colloidal quantum dots, photovoltaics, depleted heterojunction

Colloidal quantum dots (CQDs) are attractive materials for use in photovoltaic devices due to their facile solution processing, low material cost, and quantum-size-effect bandgap tunability ${ }^{[1,2]}$. Rapid progress in CQD photovoltaic device architectures and improvements in electronic material properties has led to certified AM 1.5 solar power conversion efficiencies of $8.5 \%{ }^{[3]}$.

In addition to the need to engineer materials properties and device architectures, it is important also to optimize the interface between the metal oxide electrode and the CQD absorber with the goal of improving electron extraction and slowing recombination ${ }^{[4]}$.

The majority of devices reported to date have relied on the depleted-heterojunction architecture, wherein a p-type CQD solid forms a charge-separating heterojunction with a ntype $\mathrm{TiO}_{2}$ or $\mathrm{ZnO}$ bulk transparent semiconductor ${ }^{[3,5,6]}$. Efficient electron transfer from the CQD solid to the electrode is an essential process in depleted heterojunction architecture ${ }^{[7]}$. The rate of electron transfer crucially competes with charge recombination during device operation. In addition, in the depleted-heterojunction structure, interface recombination can 
still occur when photoelectrons that have drifted or diffused to the $\mathrm{TiO}_{2}$ recombine at or near that interface with photoholes in the CQD solid. This can limit the separation of the quasiFermi levels and reduce extracted current-carrying charge carriers ${ }^{[8,9]}$. In the related field of dye-sensitized solar cells, much attention - including experimental characterization, modeling, and process improvement - has been devoted to alleviating recombination at the $\mathrm{TiO}_{2}$ electrode / dye absorber interface ${ }^{[10]}$.

Recombination at the electrode : absorber heterointerface can be modeled using a modified Shockley-Read-Hall model ${ }^{[11]}$. In this picture, reduction of interface recombination can be achieved by reducing interface carrier densities and surface recombination velocities ${ }^{[8]}$ (Supporting information Equation 2).

Modification of the interface by introduction of a buffer layer between $\mathrm{TiO}_{2}$ and the CQD film may serve to reduce interface recombination by lowing the electrode trap density and interface carrier density. The energetics of these interfaces must be finely adjusted to ensure that electrons injected into the electron acceptor are extracted prior to encountering a hole. Modifying the interface between $\mathrm{TiO}_{2}$ and CQDs with an ultra thin ALD $\mathrm{ZnO}$ buffer layer with lower surface recombination velocity can reduce the interface recombination and improve the cell open-circuit voltage $\left(\mathrm{V}_{\mathrm{oc}}\right)$. To accomplish this, the interface buffer layer is required to be not only trap-free but also properly aligned with the energy levels of $\mathrm{TiO}_{2}$ and CQDs (Figure 1) ${ }^{[12]}$. Unfavorable band alignment between $\mathrm{ZnO}$ and $\mathrm{TiO}_{2}$ was previously found to compromise the short-circuit current $\left(\mathrm{J}_{\mathrm{sc}}\right)$, resulting in only minor improvements in overall power conversion efficiency $(\mathrm{PCE})^{[13]}$.

We explore herein a new interface buffer layer with low trap density and exhibiting an electron affinity that lies that of $\mathrm{TiO}_{2}(\sim 4.1 \mathrm{eV})$ and CQDs ( 3.9 eV) (Figure 1).

CQDs blended with organic semiconductors represent a novel class of hybrid materials for optoelectronics with the potential for improved charge transport properties as well as extended and tailorable functionalities ${ }^{[14]}$. Previous works have reported a promising hybrid 
composite consisting of PbS CQDs and [6,6]-phenyl-61-butyric acid methyl ester (PCBM) ${ }^{[15]}$. The results showed that highly efficient and ultrafast electron injection takes place between PbS CQDs and PCBM, as judged from photoluminescence quenching measurements ${ }^{[16]}$. In particular, PCBM's lowest unoccupied molecular orbital (LUMO) is around $-4.0 \mathrm{eV}$ [17], which fits well with the electron affinity requirement for interface buffer layer discussed before. PCBM is also a primary choice for electron transport material in organic photovoltaics due to its low trap density and excellent electron transport ability ${ }^{[18]}$. These characteristics make PBCM an ideal candidate using as interface buffer layer in CQD solar cell (Figure S1).

To investigate PCBM as candidate buffer layers in PbS CQD solar cells, we spin-cast an ultra thin PCBM layer on a $\mathrm{TiO}_{2}$ electrode, producing a PCBM layer with average thickness $10 \pm 2 \mathrm{~nm}$. We then added a $300 \mathrm{~nm}$ thick PbS CQDs layer followed by a top ohmic contact using procedures reported previously ${ }^{[5]}$. As shown in Figure 2, initial device results demonstrated that the PCBM buffer layer led to only marginally improved power conversion efficiency through a combination of enhancements in fill factor (FF) and short-circuit current density $\left(\mathrm{J}_{\mathrm{sc}}\right)$. Unfortunately, improvements were inconsistent from pixel to pixel on the same substrate, which we ascribe to alow thickness of the PCBM layer that could not fully encapsulate the rough $\mathrm{TiO}_{2}$ surface and provide reliable interface passivation.

In order to achieve a reproducible and significant improvement in performance, we explored the role of PCBM layer thickness. We prepared and test devices with around 20, 40 and 100 nm thick PCBM layers (Table S1). The result showed that increasing the PCBM layer thickness lead to a decrease in device performance, mainly due to a loss in $\mathrm{J}_{\mathrm{sc}}$ (Table $\mathrm{S} 1$ ).

To understand the origin of $\mathbf{J}_{\mathrm{sc}}$ reduction with increasing PCBM thickness, we carried out electro-optical simulations ${ }^{[19,20]}$. The net doping level for PCBM is near-intrinsic $\left(n \sim 10^{15}\right)^{[21]}$. As shown in Figure 3a, the depletion region in the CQD film will shrink with increasing thickness of intrinsic PCBM, militating against charge extraction from the CQD layer: with 
less electric field in the device,extraction is limited to the carrier diffusion length of $\sim 100 \mathrm{~nm}$ [22].

Modeling suggested that $n$-doping of the PCBM could alleviate the problem, making PCBM part of the (free-carrier-rich) electrode rather than an additional member of the (depleted) active layer (Figure 3b).

Doping of solution-processed n-type semiconductors ${ }^{[23]}$ such as fullerenes can be achieved via blending PCBM and tetrabutylammonium salts (TBAX) to achieve high conductivity ${ }^{[24]}$. Effective electron transfer between the halide X and PCBM induces effective doping ${ }^{[24,32]}$. Meanwhile, in this work, the halide is also known to improve passivation of CQDs, leading to the stable n-type doping CQDs, which renders the approach highly compatible with the intended optimized device fabrication. We used tetrabutylammonium iodide (TBAI) salt and followed established procedures ${ }^{[21]}$. Hall effect measurements on the PCBM layer proved that its doping density increased from $10^{15}$ to $10^{18} \mathrm{~cm}^{-3}$ after TBAI treatment, in good agreement with previous results (Figure S1). To avoid losing the halide and thus doping of PCBM layer under the follow-up MPA treatment (Figure S3 and Figure S4), we treated the first two CQD layers with TBAI, and then followed with 8 layers treated using the regular MPA process to provide the required p-type doping to CQDs (Figure S7).

The device was characterized under AM 1.5 simulated solar illumination. Figure 4 reports current-voltage plot for these devices. An overall, statistically-singificant PCE enhancement of $20 \%$ was observed for the devices with the n-doped PCBM layer compared to the control device (Table S2). Uncertainties were calculated by obtaining the standard deviation across sixteen pixels fabricated on the same substrate and fabrication run. A champion dopedPCBM-based device efficiency of $8.9 \%$ (Figure S5). The enhancement was due to improvement in both $\mathrm{J}_{\mathrm{sc}}$ and $\mathrm{FF}$. These results are in good agreement with simulation, which shows that n-doping of PCBM maximized the depletion region in CQD layer allowing for 
better charge extraction from CQDs - consistent with our experimental observation of both improved $\mathrm{J}_{\mathrm{sc}}$ and $\mathrm{FF}$.

To better understand how the addition of n-doping PCBM leads to improved performance, we carried out light-biased $\mathrm{V}_{\text {oc }}$ transient analysis ${ }^{[25]}$. Transient photovoltage measurements were used to measure the recombination rate as a function of $\mathrm{V}_{\mathrm{oc}}$. The methodology was adapted from previous work conducted on polythiophene : Fullerene solar cells. The recombination rate, $\mathrm{R}$, can be calculated using the injected carrier density $\mathrm{n}$ and the carrier life time, $\tau$. Carrier recombination for both $n$-doping PCBM coated $\mathrm{TiO}_{2}$ and $\mathrm{TiO}_{2}$ control were compared ${ }^{[26]}$. Recombination rates as a function of $\mathrm{V}_{\mathrm{oc}}$ show a nearly two-fold reduction after the introduction of the n-doping interface layer near 1 sun operating condition. The reduction in the recombination rate for the n-doped PCBM coated device is due almost entirely to the reduced injection carrier densities as opposed to improvements in the carrier lifetime. $\mathrm{V}_{\mathrm{oc}}$ decay measurements show that the concentration of photo-generated carriers decreases when n-doped PCBM is present while the recombination lifetime increases. This means that apart from passivating the interface traps, n-doped PCBM layer also enhances the injection of carriers from $\mathrm{PbS}$ into the electrode, leading to lower accumulated carrier density in $\mathrm{PbS}$.

We note that recent works on perovskite solar cells have also used a PCBM monolayer on mesoporous $\mathrm{TiO}_{2}$ electrodes ${ }^{[27,28]}$. This has been found to accelerate charge extraction, an improvement attributed to improved mobility of electrons in PCBM compared to $\mathrm{TiO}_{2}$. The device reported herein has, by contrast, a planar architecture, and better transport within the added intervening layer is not the primary source of benefit. Instead, reduced interface recombination dominates the improvement. We note also that previous studies of PCBM as the main electron transporting electrode in CQD solar cells ${ }^{[15]}$ led to suboptimal performance, and we suggest that the $\mathrm{TiO}_{2}: \mathrm{PCBM}$ combination is highly desirable, with PCBM acting as an intermediate-energy relay on the path to the $\mathrm{TiO}_{2}$ in which electrons are rapidly swept to the 
FTO (Figure S2). Our results also indicate that, only with the deliberate doping of PCBM, is a substantial net performance improvement achieved.

Electrode interfaces have a sizeable contribution to recombination losses in CQD solar cells. We showed herein that PCBM can be used successfully as a low trap density buffer layer at interface, reducing interface recombination. In addition, its usefulness for device operation depends critically on maintaining its doping level close to that of the electrode. The work demonstrates an attractive synergy between best materials from organic and inorganic nanomaterials photovoltaics.

\section{Experimental Section}

\section{$\mathrm{TiO}_{2}$ Deposition.}

Atomic layer deposition (ALD) of $\mathrm{TiO}_{2}$ was carried out in a Cambridge NanoTech ALDSavannah system at $150{ }^{\circ} \mathrm{C}$ using Tetrakis(dimethylamido)titanium (IV) (TDMAT) and water $\left(\mathrm{H}_{2} \mathrm{O}\right)$, as the metallic precursor and oxygen source, respectively. The TDMAT precursor was heated to $75{ }^{\circ} \mathrm{C}$. Growth per cycle (GPC) was $0.45 \pm 0.01 \AA /$ cycle for the titanium dioxide as measured by spectroscopic ellipsometry. Each ALD cycle included a $100 \mathrm{~ms}$ TDMAT precursor dose followed by a $20 \mathrm{~s}$ nitrogen gas purge step and a $15 \mathrm{~ms} \mathrm{H}_{2} \mathrm{O}$ precursor dose followed by $20 \mathrm{~s}$ of purging. The substrates were further placed in a $120 \mathrm{mmol}$ solution of $\mathrm{TiCl}_{4}$ in deionized (DI) water and heated in an oven for $30 \mathrm{~min}$ at $70{ }^{\circ} \mathrm{C}$. Next, the samples were removed from the solution, rinsed with DI water and sintered on a hot plate for 45 min at $520^{\circ} \mathrm{C}$.

\section{Photovoltaic Device Fabrication.}

N-doped PCBM solution was prepared in the nitrogen glovebox according to following procedure. $0.81 \mathrm{mg}$ tetrabutylammonium iodide (TBAI) was dissolved in $1 \mathrm{ml}$ anhydrous chloroform, then $20 \mathrm{mg}$ PCBM was introduced to the system. The resulting mixture was 
stirred for $5 \mathrm{~h}$ at room temperature. Then, the n-doped PCBM layer was deposited on the $\mathrm{TiO}_{2}$ / FTO substrate and spin-cast at 2500 rpm for 20 seconds. PbS CQD films were deposited using a layer-by-layer spin-casting process. For the first two layers, $\mathrm{PbS}$ CQDs in octane (50 $\mathrm{mg} / \mathrm{mL})$ were spin-cast at $2500 \mathrm{rpm}$ for 10 seconds. A TBAI solution $(10 \mathrm{mg} / \mathrm{mL}$ in methanol) was then applied to the film for $30 \mathrm{~s}$, followed by two rinse-spin steps with methanol. For PbS-MPA layers, a methanol solution containing $1 \%$ by volume MPA was used for the ligands exchange process, followed by two times methanol washing to remove unbound ligands. All the spin-coating steps were performed under ambient condition at room temperature. Top electrodes were deposited using an Angstrom Engineering deposition system in an Innovative Technology glovebox. The contacts typically consisted of $40 \mathrm{~nm}$ thermally evaporated molybdenum trioxide deposited at a rate of $0.2 \AA \mathrm{S}^{-1}$, followed by electron-beam deposition of $50 \mathrm{~nm}$ of gold deposited at $0.4 \AA \mathrm{S}^{-1}$, and finally $200 \mathrm{~nm}$ of thermally evaporated silver deposited at $1.0 \AA \mathrm{S}^{-1}$.

\section{Photovoltaic performance characterization.}

Current-voltage characteristics were measured using a Keithley 2400 source-meter in $\mathrm{N}_{2}$ ambient. The solar spectrum at AM1.5 was simulated to within class A specifications (less than $25 \%$ spectral mismatch) with a Xe lamp and filters (Solar Light Company Inc.) with measured intensity at $100 \mathrm{~mW} \mathrm{~cm}$. The source intensity was measured using a Melles-Griot broadband power meter and a Thorlabs broadband power meter through a circular $0.049 \mathrm{~cm}^{2}$ aperture at the position of the device and confirmed with a calibrated reference solar cell (Newport, Inc.). The accuracy of the power measurement was estimated to be $\pm 5 \%$.

\section{Transient photovoltage measurements.}

In the photovoltage transient method, a $630 \mathrm{~nm}$ diode laser is used to modulate the $\mathrm{V}_{\text {OC }}$ on top of a constant light bias. The pulse duration is set to $1 \mu$ s and the repetition rate to $50 \mathrm{~Hz}$. For the constant light bias, a continuous wave $830 \mathrm{~nm}$ fibre-coupled diode laser is collimated on 
the active area of the solar cell under study, and photovoltage transients are measured over an equivalent intensity range of 0.0001 - 5 suns, ensuring coverage of the full range of $\mathrm{V}_{\mathrm{OC}}$ 's. The intensity of the pulsed laser was set so that the modulated $\mathrm{V}_{\mathrm{OC}}$ was less than $10 \mathrm{mV}$ for $\mathrm{V}_{\mathrm{OC}}$ 's larger than $100 \mathrm{mV}$, and around $5 \mathrm{mV}$ for $\mathrm{V}_{\mathrm{OC}}$ 's for less than $100 \mathrm{mV}$, to ensure a perturbation regime. The open circuit voltage transient, induced by the light perturbation was measured with a digital oscilloscope set to an input impedance of $1 \mathrm{M} \Omega$. The total charge injected from the perturbation pulse was measured from the integration of the laser induced transient signal with the device at $\mathrm{J}_{\mathrm{sc}}$ conditions.

\section{Optoelectronic Simulation.}

Optoelectronic simulations were performed in SCAPS 3.0.01 modeling program. Ohmic boundary conditions were imposed on both sides. An AM $1.5 \mathrm{G}$ illumination spectrum was used for the device excitation. A full material parameter list is provided in Supplementary Information (Table S3). A band-gap of $1.1 \mathrm{eV}$ was used for CQDs to account for the difference between the optical and electronic bandgaps and density of states tails. Neutral defects were introduced $0.25 \mathrm{eV}$ below the conduction band of CQDs as a single effective level with a $10^{16} \mathrm{~cm}^{-3}$ density and capture cross-sections adjusted to achieve the experimentally observed diffusion length of $80 \mathrm{~nm}{ }^{[7]}$ and lifetime of $120 \mathrm{~ns}{ }^{[29]}$ for a chosen mobility of $2 \times 10^{-2} \mathrm{~cm}^{2} \mathrm{~V}^{-1} \mathrm{~s}^{-1[30]}$. Neutral interface traps were introduced at the $\mathrm{TiO}_{2}-\mathrm{CQD}$ interface with a $10^{12} \mathrm{~cm}^{-2}$ surface density. Electron affinity of $4 \mathrm{eV}$ was used for PCBM, in between those of $\mathrm{TiO}_{2}$ and CQDs, allowing for an easy electron transfer from CQDs to PCBM, as suggested by photoluminescence quenching experiments ${ }^{[16,31]}$.

\section{Supporting Information}

Supporting Information is available from the Wiley Online Library or from the author.

\section{Acknowledgements}

This publication is based in part on work supported by Award KUS-11-009-21, made by King Abdullah University of Science and Technology (KAUST), by the Ontario Research Fund Research Excellence Program, and by the Natural Sciences and Engineering Research Council (NSERC) of Canada. We thank Angstrom Engineering and Innovative Technology 
for useful discussions regarding material deposition methods and control of glovebox environment, respectively. The authors would like to acknowledge the technical assistance and scientific guidance of E. Palmiano, R. Wolowiec, and D. Kopilovic.

Received: ((will be filled in by the editorial staff))

Revised: ((will be filled in by the editorial staff)) Published online: ((will be filled in by the editorial staff))

[1] E. H. Sargent, Nat. Photonics. 2012, 6, 133.

[2] M. Grätzel, R. A. J. Janssen, D. B. Mitzi, E. H. Sargent, Nature. 2012, 488, 304.

[3] C-H. M. Chuang, P. B. Brown, V. Bulović, M. G. Bawendi. Nature. Mater. 2014, 13, 796.

[4] I. J. Karmer, E. H. Sargent, Chem. Rev. 2014,114, 863.

[5] A. H. Ip, S. M. Thon, S. Hoogland, O. Voznyy, D. Zhitomirsky, R. Debnath, L. Levina, L. R. Rollny, G. H. Carey, A. Fischer, K. W. Kemp, I. J. Kramer, Z. Ning, A. J. Labelle, K.W. Chou, A. Amassian, E. H. Sargent, Nat. Nanotech. 2012, 7, 577.

[6] M. Yuan, D. Zhitomirsky, V. Adinolfi, O. Voznyy, K. W. Kemp, Z. Ning, X. Lan, J. Xu, J. Y. Kim, H. P. Dong, E. H. Sargent, Adv. Mater. 2013, 25, 5586.

[7] D. Zhitomirsky, O. Voznyy, L. Levina, S. Hoogland, K. W. Kemp, A. H. Ip, S. M. Thon, E. H. Sargent, Nat. Commun. 2014, 5, 3803.

[8] K. W. Kemp, A. J. Labelle, S. M. Thon, A. H. Ip, I. J. Karmer, S. Hoogland, E. H. Sargent, Adv. Energy. Mater.2013, 3, 917.

[9] J. K. Kroeze, N. Hirata, S. Koops, M. K. Nazeeruddin, L. Schmidt-Mende, M. Grätzel, J. R. Durrant, J. Am. Chem. Soc. 2006, 128, 16376.

[10] P. P. Boix, A. Guerrero, L. F. Marchesi, G. Garcia-Belmonte, J. Bisquert. Adv. Energy. Mater.2011, 1, 1073.

[11] R. Scheer, H. -W. Schock, In Chalcogenide Photovoltaics; Wiley-VCH, Weinheim, 2011; pp. 9-27;

[12] A. G. Pattantyus-Abraham, I. J. Kramer, A. R. Barkhouse, X. Wang, G. Konstantatos, R. 
Debnath, L. Levina, I. Raabe, M. K. Nazeeruddin, M. Gratzel, E. H. Sargent, ACS Nano. 2010, 4, 3374.

[13] J. Kim, O.Voznyy, D. Zhitomirsky, E. H. Sargent, Adv. Mater. 2013, 25, 4986.

[14] Z. Liu, Y. Sun, J. Yuan, H. Wei, X. Huang, L. Han, W. Wang, H. Wang, W. Ma, Adv. Mater. 2013, 25, 5772.

[15] N. Zhao, T. P. Osedach, L. Chang, S. M. Geyer, D. Wanger, M. T. Binda, A. C. Arango, M. G. Bawendi, V. Bulović, ACS Nano. 2010, 4, 3743.

[16] A. O. El-Ballouli, E. Alarousu, M. Bernardi, S. M. Aly, A. P. Lagrow, O. M. Bakr, O. F. Mohammed, J. Am. Chem. Soc. 2014, 136, 6952.

[17] A. Gocalinska, M. Saba, F. Quochi, M. Marceddu, K. Szendrei, J. Gao, M. A. Loi, M. Yarema, R. Seyrkammer, W. Heiss, A. Mura, G. Bongiovanni, J. Phys. Chem. Lett, 2010, $1,1149$.

[18] K. Chen, H. Yip, J. Salinas, Y. Xu, C. Chueh. A. K. - Y. Jen, Adv. Mater.2014, 26, 3349.

[19] M. Burgelman, P. Nollet, S. Degrave, Thin Solid Films. 2000, 361-362, 527.

[20] M. Burgelman, J. Verschraegen, S. Degrave, P. Nollet, Prog. Photovolt: Res. Appl. 2004, $12,143$.

[21] C. Li, C. Chueh, F. Ding, H. Yip, P. Liang, X. Li, A. K. -Y. Jen, Adv. Mater.2013, 25, 4425.

[22] D. Zhitomirsky, M. Furukawa, J. Tang, P. Stadler, S. Hoogland, O. Voznyy, H. Liu, E. H. Sargent, Adv. Mater. 2012, 24, 6181.

[23] C. Li, C. Chang, Y. Zhang, H. Ju, C. Chueh, P. Liang, N. Cho, D. Ginger, A. K. -Y. Jen, Adv. Mater. 2014, 26, 6262.

[24] C. Li, C. Chueh, H. Yip, F. Ding, X. Li, A. K. -Y. Jen, Adv. Mater. 2013, 25, 2457.

[25] B. C.O'Regan, S.Scully, A. C.Mayer, E.Palomares, J.Durrant, J. Phys. Chem. B. 2005, 109, 4616-4623.

[26] C. G. Shuttle, B. O'Regan, A. M. Ballantyne, J. Nelson, D. D. C. Bradley, J.de Mello, J. 
R. Durrant, Appl. Phys. Lett. 2008, 92, 093311.

[27] A. Abrusci, S. D. Stranks, P. Docampo, H. Yip, A. K. -Y. Jen, H. J. Snaith, Nano Lett. 2013, 13, 3124 .

[28] P. Docampo, J. M. Ball, M. Darwich, G. E. Eperon, H. J. Snaith. Nat. Commun. 2013, 4,2761

[29] Y. Yang, W. Rodríguez-Córdoba, X. Xiang, T. Lian, Nano Lett. 2012, 12, 303.

[30] D. Zhitomirsky, O. Voznyy, S. Hoogland, E. H. Sargent, ACS Nano. 2013, 7, 5282.

[31] N. Song, H. Zhu, S. Jin, T. Lian, ACS Nano. 2011, 5, 8750.

[32] C. D. Weber, C. Bradley, M. C. Lonergan, J. Mater. Chem. A. 2014, 2, 303. 

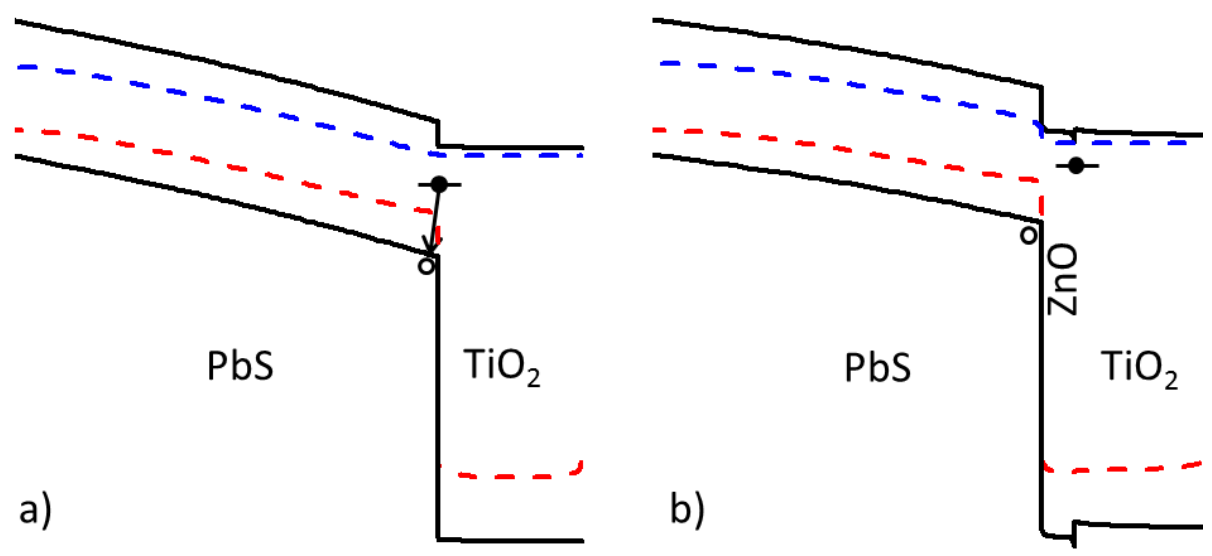

Figure 1. The interface buffer layer and its band alignment. (a) Traditional depletedheterojunction CQD devices. (b) Previously-reported CQD PV devices that add an interfacial $\mathrm{ZnO}$ layer 


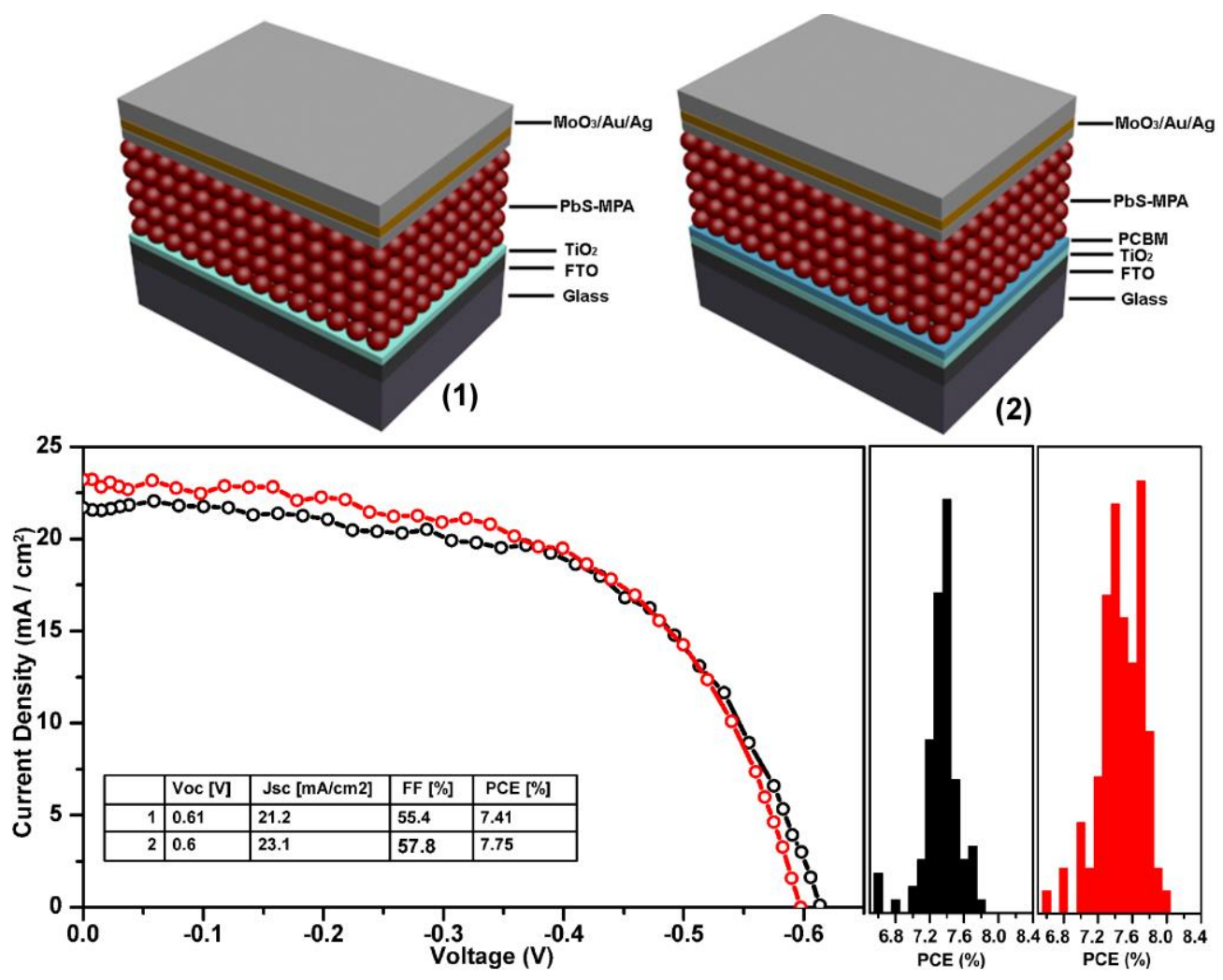

Figure 2. Device performance and performance distribution with / without PCBM interfacial buffer layer. The top images show the control (left) and new (right) device. Below are shown current-voltage characteristics of the control (black) and new (red) device, as well as PCE distribution histograms. 

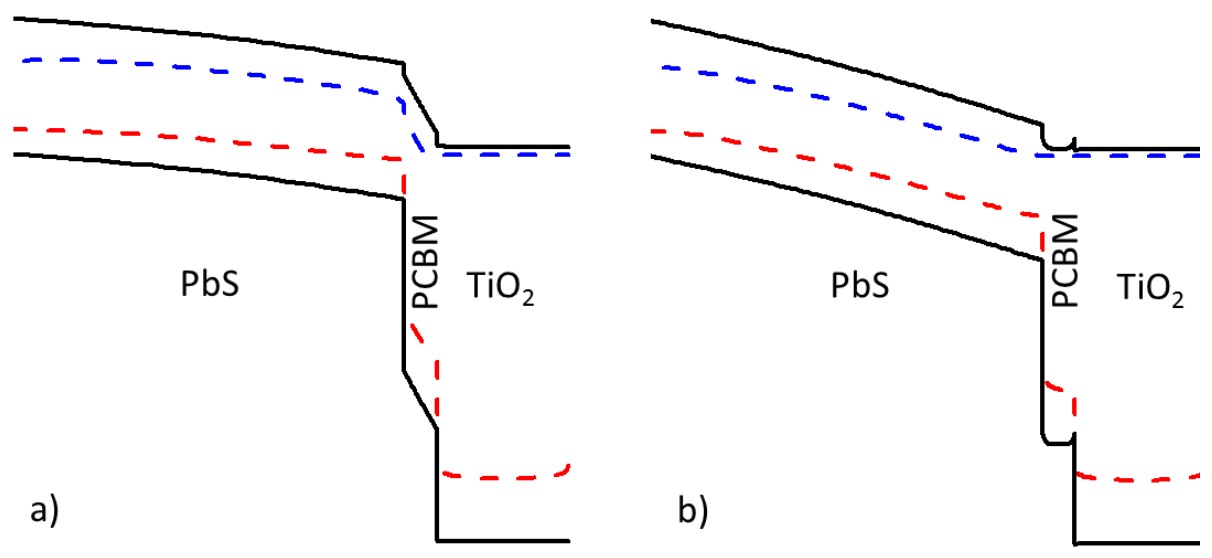

Figure 3. Effect of PCBM interfacial buffer layer with/without doping. Spatial band diagrams for (a) intrinsic PCBM and (b) for n-type PCBM. 


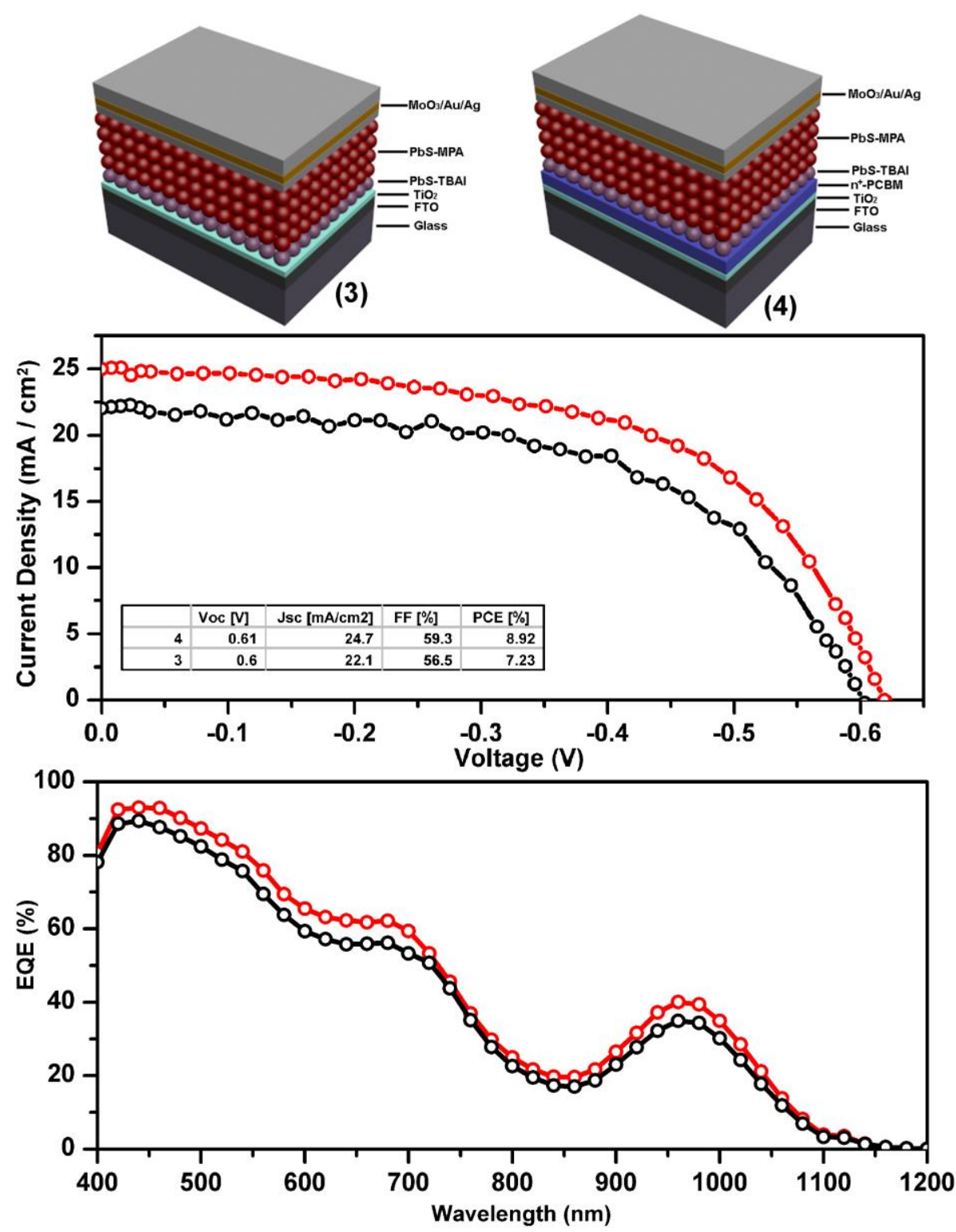

Figure 4. Device performance and EQE spectra with /without $\mathrm{N}$ doping PCBM buffer layer. The top images represent the control (left) and n-PCBM (right) devices. Black lines report the control, red the n-PCBM. The upper plot shows current-voltage, the lower the external quantum efficiency (EQE) spectrum. 

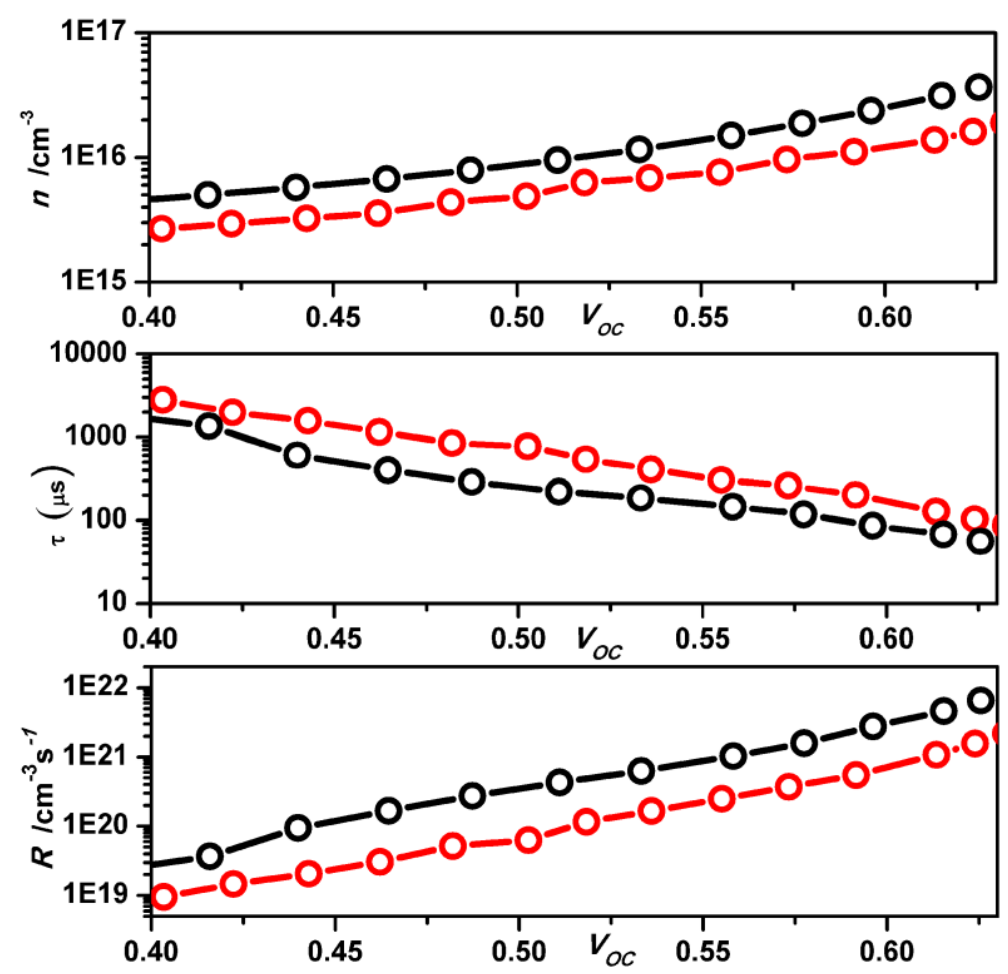

Figure 5. Summary of recombination analysis with / without n-doping PCBM buffer layer. The top panel shows the excess electron density as a function of $\mathrm{V}_{\mathrm{oc}}$. The middle panel shows the carrier lifetime in microseconds as a function of $\mathrm{V}_{\mathrm{oc}}$. The lower shows the recombination rate in $\mathrm{cm}^{-3} \mathrm{~s}^{-1}$ as a function of $\mathrm{V}_{\mathrm{oc}}$. In each case, black represents control devices, red represents n-doping PCBM devices. 


\section{The table of contents entry:}

Understanding and reducing recombination is an essential avenue to improving the performance of colloidal quantum dot (CQD) solar cells. Here we identify the spatial location ofthe predominant source of performance-limiting recombination in today's best CQD cells, pinpointing the $\mathrm{TiO}_{2}$ :CQD junction; and introduce a PCBM layer, doped highly n-type in situ during processing, at the planar $\mathrm{CQD}: \mathrm{TiO}_{2}$ heterointerface. Using transient photovoltage measurements, we show that the new interfacial layer produces a two-fold reduction in the rate of recombination. We find that n-doping the PCBM layer is essential to maintain the depletion region within the CQD layer and thereby allow for efficient current extraction. These improvements to device architecture resulted in enhanced charge collection efficiency and fill factor, producing a 1.2-fold improvement in overall solar power conversion efficiency, leading to a record $8.9 \%$ PCE.

Keyword: PbS, PCBM, colloidal quantum dots, photovoltaics, depleted heterojunction;

By Mingjian Yuan, ${ }^{\ddagger}$ Oleksandr Voznyy, ${ }^{\ddagger}$ David Zhitomirsky, Pongsakorn Kanjanaboos, Edward H.

Sargent*

Synergistic Doping of Fullerene Electron Transport Layer and Colloidal Quantum Dot Solids Enhances Solar Cell Performance
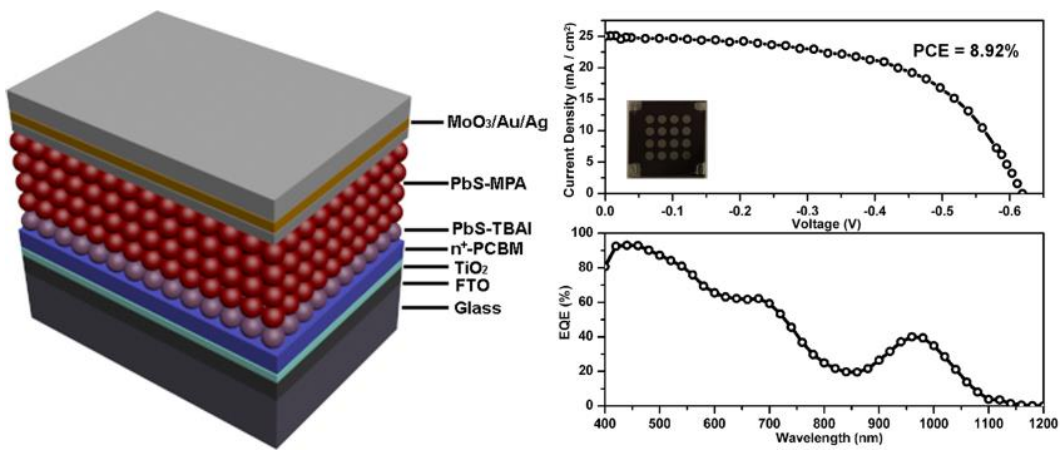


\section{Supporting Information}

Synergistic Doping of Fullerene Electron Transport Layer and Colloidal Quantum Dot Solids Enhances Solar Cell Performance

Mingjian Yuan, ${ }^{+}$Oleksandr Voznyy, ${ }^{+}$David Zhitomirsky, Pongsakorn Kanjanaboos, Edward H. Sargent*

[*] Prof. E. H. Sargent, Dr. M. Yuan, Dr. O. Voznyy, Dr. D. Zhitomirsky, Dr. P. Kanjanaboos

Department of Electrical and Computer Engineering, University of Toronto, 10 King's College Road, Toronto, Ontario, M5S 3G4, Canada

E-mail: ted.sargent@utoronto.ca 

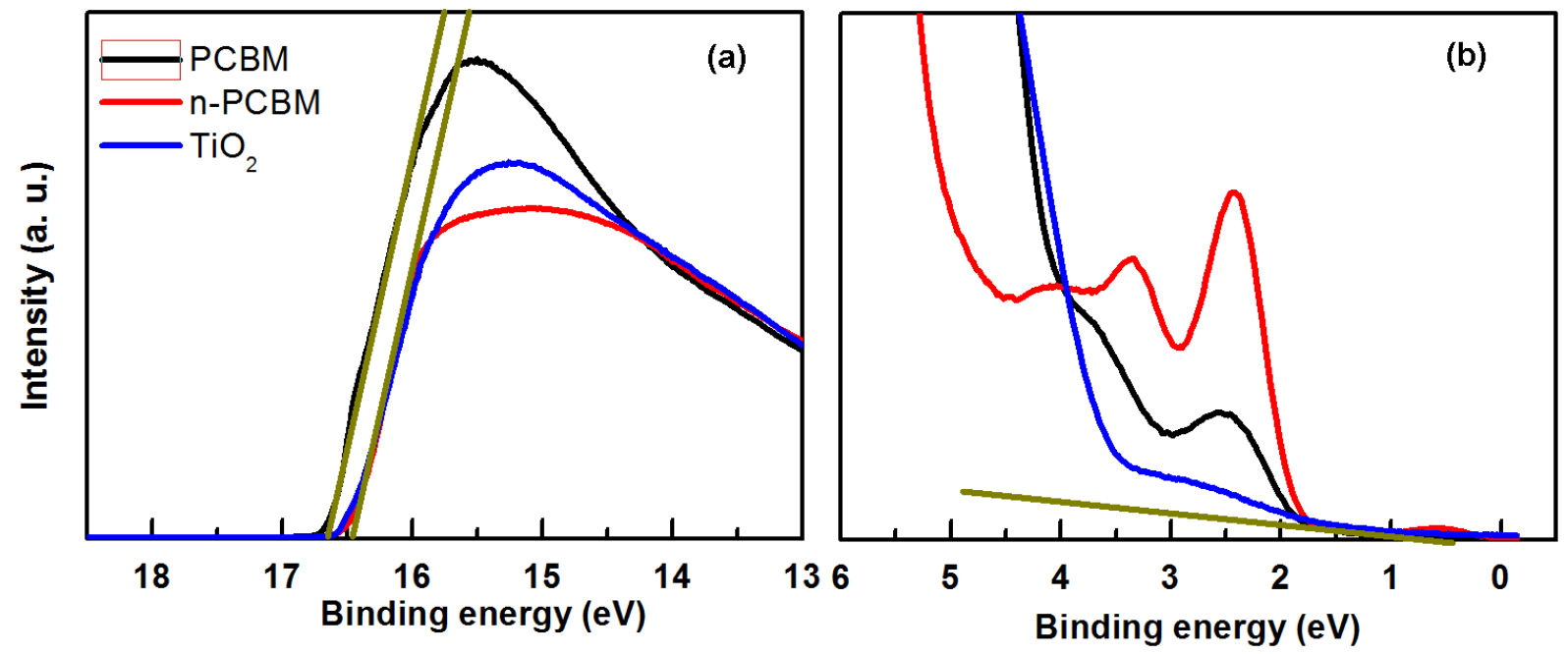

Figure S1. Electronic properties of PCBM, n-PCBM and $\mathrm{TiO}_{2}$ films. (a) Secondary edge region of ultraviolet photoelectron spectra (UPS) of PCBM, n-PCBM and $\mathrm{TiO}_{2}$. (b) Low energy onset region of UPS spectra of PCBM, n-PCBM and $\mathrm{TiO}_{2}$ plotted relative to an $\mathrm{Au}$ reference. 


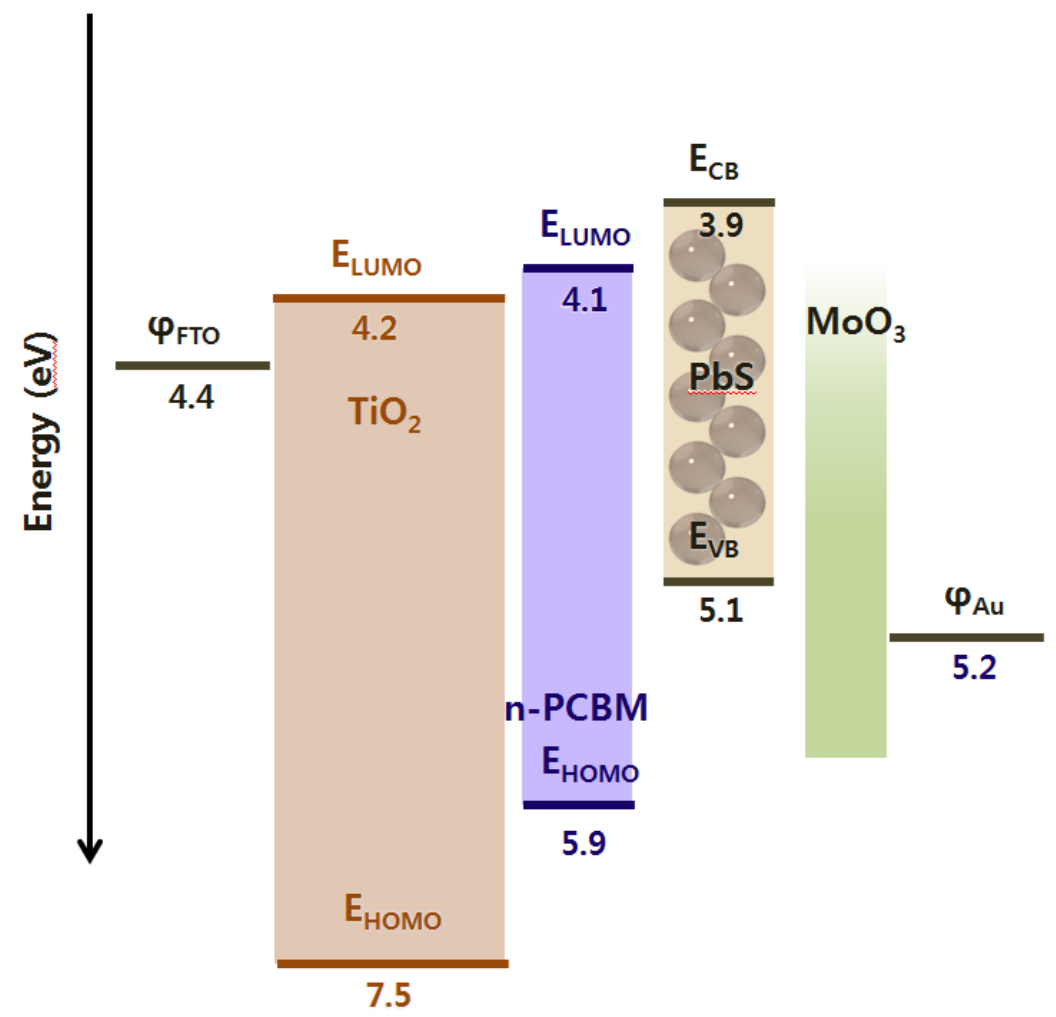

Figure S2. Energy level diagrams of device $\mathrm{FTO} / \mathrm{TiO}_{2} / \mathrm{n}-\mathrm{PCBM} / \mathrm{PbS} / \mathrm{MoO}_{3} / \mathrm{Au}$ conduction band $\left(\mathrm{E}_{\mathrm{CB}}\right)$, valence band $\left(\mathrm{E}_{\mathrm{VB}}\right)$ and Fermi energies $\left(\mathrm{E}_{\mathrm{F}}\right)$ of $\mathrm{n}-\mathrm{PCBM}$ and $\mathrm{TiO}_{2}$ films derived from UPS data. 


\section{Schockley-Read-Hall Model ${ }^{[\mathrm{S} 1, \mathrm{~S} 2]}$ :}

(a) The interfacial recombination rate can be established using the following equation:

$\mathrm{R}=\frac{P_{a, z=0} N_{w, z=0}}{S_{n}^{-1} P_{a, z=0}+S_{p}^{-1} N_{w, z=0}}-$--------- equation (S1)

$\mathbf{P}_{\mathbf{a}}$ and $\mathbf{N}_{\mathbf{w}}$ are the hole and electron concentration at the interface in the absorber and electrode materials. $\mathbf{S}_{\mathbf{n}}$ and $\mathbf{S}_{\mathbf{p}}$ represent the surface recombination velocities for electron in the electrode and holes in the absorber.

For a highly n doped electrode, $\mathbf{N}_{\mathbf{w}, \mathbf{z}=\mathbf{0}}>>\mathbf{P}_{\mathbf{w}, \mathbf{z}=\mathbf{0}}$, the recombination rate from Equation (1) can be reduced to

$\mathrm{R}=\mathrm{S}_{\mathrm{p}} \mathrm{P}_{\mathrm{a}, \mathrm{z}=0} \quad$--------- equation $(\mathbf{S 2})$

(b) The surface recombination velocities, $\mathbf{S}_{\mathbf{n}, \mathbf{p}}$, can be given by:

$\mathrm{S}_{\mathrm{n}, \mathrm{p}}=v_{\mathrm{th}} \sigma_{\mathrm{n}, \mathrm{p}} \mathrm{N}_{\mathrm{d}} \quad--------\quad$ equation $(\mathbf{S 3})$

$\mathbf{N}_{\mathbf{d}}$ is the interface trap density, $\boldsymbol{\sigma}_{\mathbf{n}, \mathbf{p}}$ is the carrier capture cross section of the trap for holes and electrons. vth is the thermal velocity of the materials .

(c) The absorber hole density at the interface, $\mathbf{P}_{\mathbf{a}, \mathbf{z}=\mathbf{0}}$, can be expressed as:

$\mathrm{P}_{\mathrm{a}, \mathrm{z}=0}=\mathrm{N}_{v} \exp \frac{q V-\phi_{b}}{k T} \quad$ equation ------- (S4)

$\mathbf{N}_{\boldsymbol{v}}$ is the valence band effective density of states, $\mathbf{k}$ is the Boltzmann constant, $\mathbf{q}$ is the elementary charge, $\mathbf{V}$ is applied voltage, $\mathbf{T}$ is the temperature and $\phi_{b}$ is the potential barrier height. 


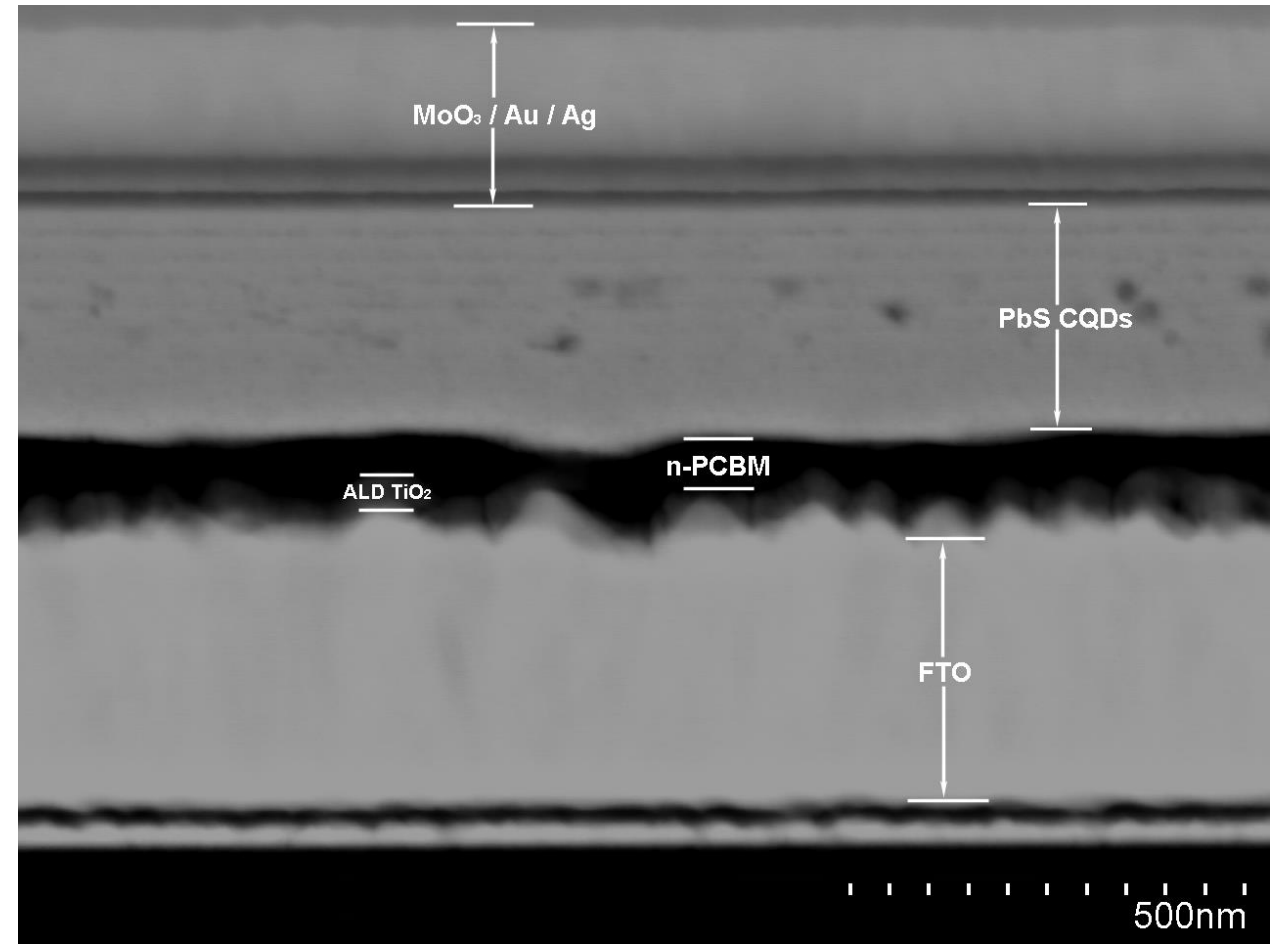

Figure S3. FIB-SEM image of the photovoltaic device with n-doping PCBM interfacial buffer layer. 

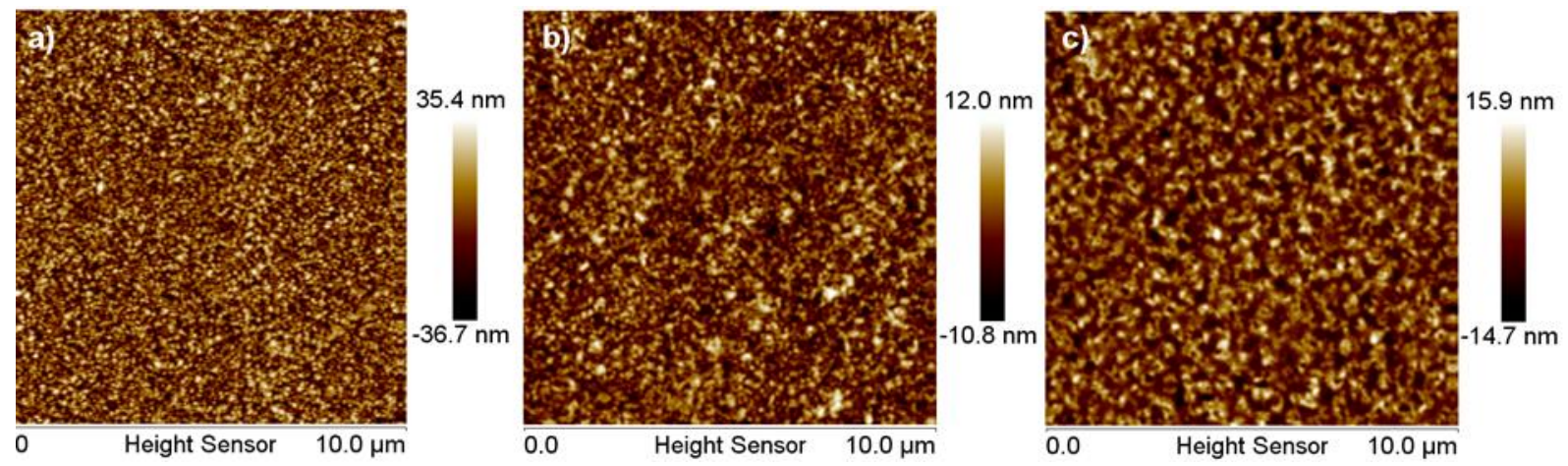

Figure S4. AFM image of the $\mathrm{ALD} \mathrm{TiO}_{2}$ electrode (a), then coated with a PCBM (b) and $\mathrm{n}$ dping PCBM (c) layer. The square roughness $\left(\mathrm{R}_{\mathrm{q}}\right)$ measured for $\mathrm{ALD} \mathrm{TiO}_{2}$ is $15.3 \mathrm{~nm}, \mathrm{PCBM}$ is $3.37 \mathrm{~nm}$ and $4.5 \mathrm{~nm}$ for $\mathrm{n}$-doping PCBM. 
Table S1. The device performance for including different thickness of PCBM interfacial buffer layer.

\begin{tabular}{|c|c|c|c|c|c|c|}
\hline PCBM Thickness & Voc $(\mathrm{V})$ & $\mathrm{Jsc}\left(\mathrm{mA} \mathrm{cm}^{-2}\right)$ & FF $(\%)$ & Rser $\left(\mathrm{Ohm} \mathrm{cm}^{-2}\right)$ & Rsh $\left(\mathrm{Ohm} \mathrm{cm}^{-2}\right)$ & PCE(\%) \\
\hline $0 \mathrm{~nm}$ & 0.61 & 21.2 & 55.4 & 7.63 & 5367 & 7.41 \\
\hline $10 \pm 2 \mathrm{~nm}$ & 0.6 & 23.1 & 57.8 & 6.48 & 14682 & 7.75 \\
\hline $24 \pm 4 \mathrm{~nm}$ & 0.6 & 20.6 & 55.7 & 7.89 & 8321 & 6.86 \\
\hline $43 \pm 7 \mathrm{~nm}$ & 0.59 & 16.7 & 50.2 & 9.13 & 3529 & 5.21 \\
\hline $100 \pm 11 \mathrm{~nm}$ & 0.57 & 14.2 & 43.3 & 10.5 & 2401 & 3.59 \\
\hline
\end{tabular}




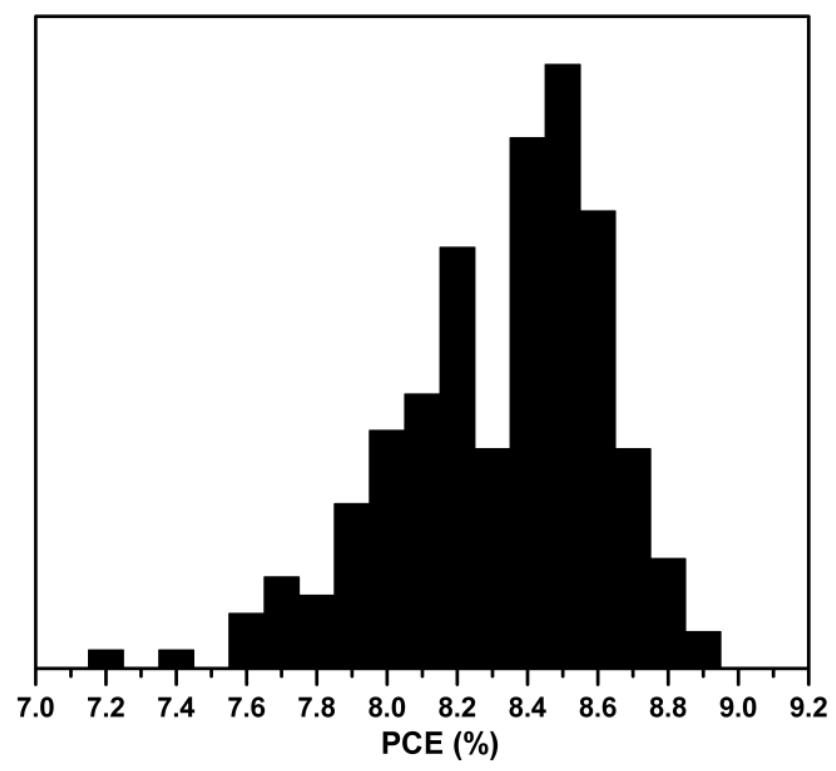

Figure S5. Power Conversion Efficiency distribution histograms of devices with doped PCBM as interfacial buffer layer. The champion device we got with PCE of $8.92 \%$. 
Table S2. Device performance using different thickness of n-doped PCBM interfacial buffer layer and different concentration of dopant. ${ }^{(1)}$ thickness measured from AFM and ${ }^{(2)}$ thickness measured from FIB-SEM

\begin{tabular}{|c|c|c|c|c|c|c|c|}
\hline $\begin{array}{l}\text { Thickness of } \\
\text { Doped PCBM }\end{array}$ & $\begin{array}{l}\text { Doping Concentration } \\
\text { (in molar Ratio) }\end{array}$ & $\operatorname{Voc}(\mathrm{V})$ & $\mathrm{Jsc}\left(\mathrm{mA} \mathrm{cm}^{-2}\right)$ & $\mathrm{FF}(\%)$ & Rser(Ohm cm cm $\left.^{-2}\right)$ & $\operatorname{Rsh}\left(\mathrm{Ohm} \mathrm{cm}^{-2}\right)$ & $\overline{\mathrm{PCE}(\%)}$ \\
\hline $32 \mathrm{~nm} \pm 4 \mathrm{~nm}^{(1)}$ & $10 \%$ & 0.6 & 23.4 & 57.7 & 6.01 & 8692 & 8.10 \\
\hline $60 \mathrm{~nm} \pm 10 \mathrm{~nm}^{(2)}$ & $10 \%$ & 0.61 & 24.7 & 59.3 & 4.47 & 11642 & 8.92 \\
\hline $83 \mathrm{~nm} \pm 6 \mathrm{~nm}^{(1)}$ & $10 \%$ & 0.61 & 24.5 & 57.3 & 4.63 & 8457 & 8.58 \\
\hline $130 \mathrm{~nm} \pm 8 \mathrm{~nm}^{(1)}$ & $10 \%$ & 0.61 & 23.7 & 55.2 & 5.81 & 6473 & 7.99 \\
\hline $57 \mathrm{~nm} \pm 6 \mathrm{~nm}^{(1)}$ & $1 \%$ & 0.6 & 22.5 & 57.1 & 6.96 & 8021 & 7.69 \\
\hline $61 \mathrm{~nm} \pm 4 \mathrm{~nm}^{(1)}$ & $5 \%$ & 0.6 & 23.8 & 58.8 & 5.79 & 9709 & 8.41 \\
\hline $53 \mathrm{~nm} \pm 3 \mathrm{~nm}^{(1)}$ & $10 \%$ & 0.61 & 24.3 & 60.2 & 4.73 & 15827 & 8.89 \\
\hline $58 \mathrm{~nm} \pm 3 \mathrm{~nm}^{(1)}$ & $20 \%$ & 0.61 & 24.1 & 57.9 & 4.85 & 7982 & 8.53 \\
\hline $66 \mathrm{~nm} \pm 7 \mathrm{~nm}^{(1)}$ & $30 \%$ & 0.6 & 23.3 & 53.2 & 6.02 & 4286 & 7.53 \\
\hline
\end{tabular}



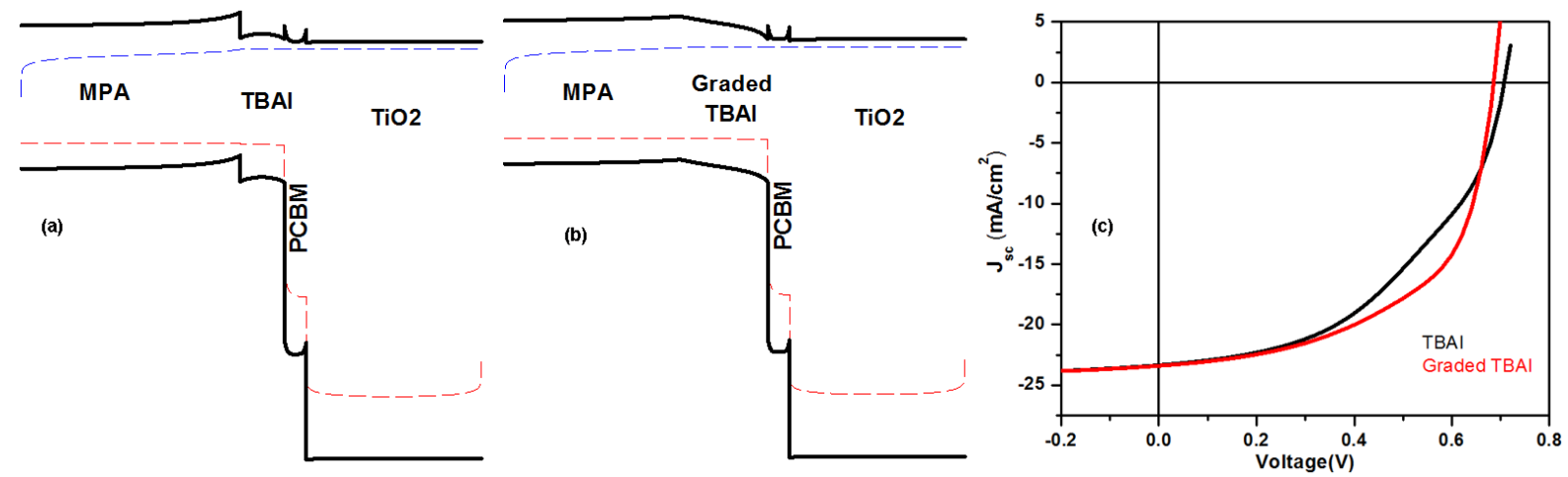

Figure S6. Optoelectronic simulation of the effect of TBAI buffer layer on the device performance. a) Band diagram of the device at Voc condition. N-type TBAI layers possess higher electron affinity relative to P-type MPA due to stronger electron-withdrawing character of the iodide ligand. A diode in reverse direction is formed, exemplified by the $\mathrm{S}$-shape of the $\mathrm{J}-\mathrm{V}$ curve. b) Electron affinity of the buffer layer is graded from electron affinity of MPA to that of TBAI. Such a grading is expected due to soaking of MPA into the underlying TBAI layers during layer-by-layer film preparation. The reverse band-bending is avoided while an additional tilt helping charge carrier collection is maintained even at $\mathrm{V}_{\text {oc. }}$ c) Simulated J-V curves for both cases. 

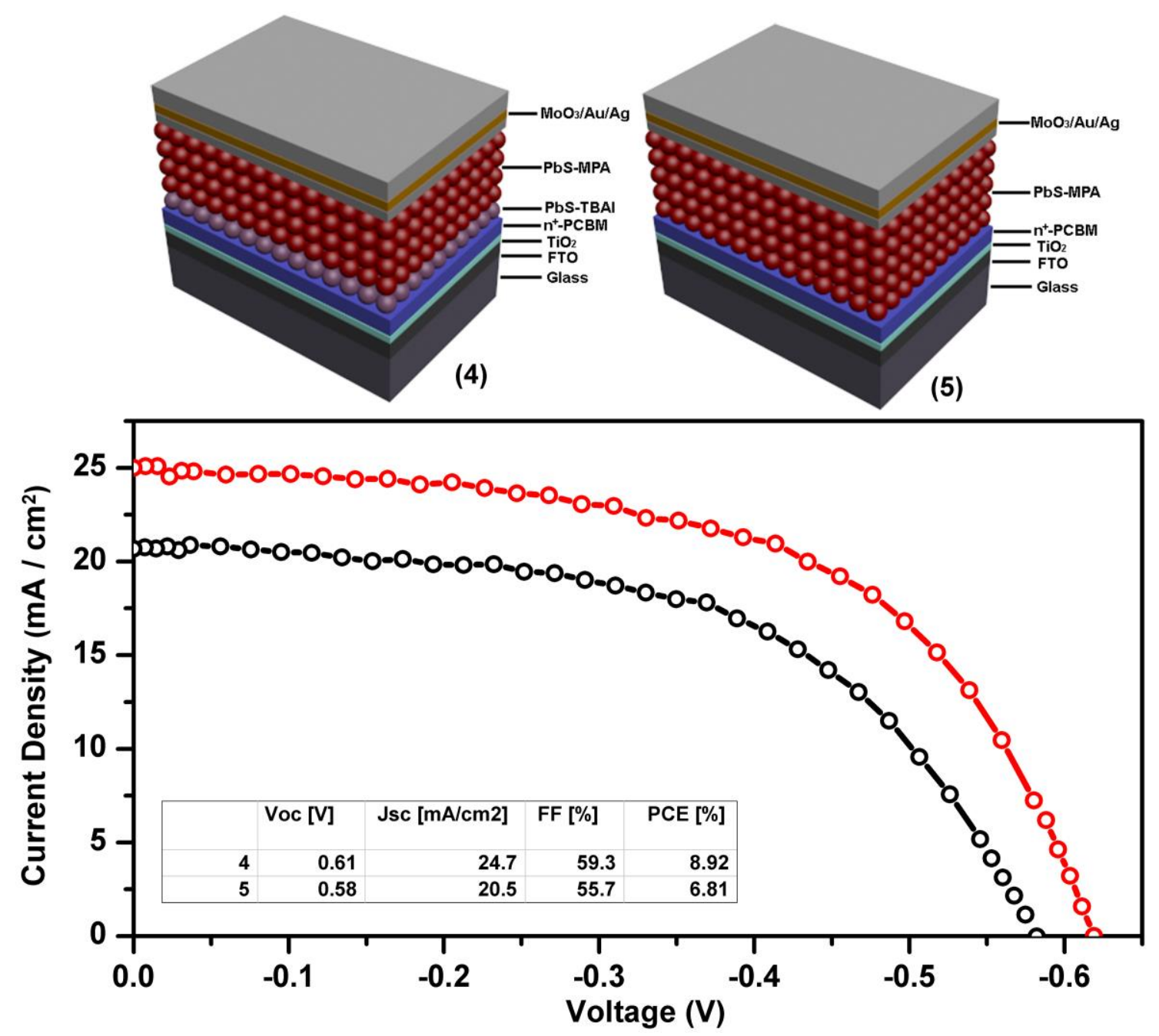

Figure S7. Device performance with /without bottom PbS-TBAI layer. The top images represent the with TBAI layer (left) and without TBAI (right) devices. Black lines report the right, red the left. Result shows the bottow two TBAI layers are important to help for keeping high doping density of n-doping PCBM. 

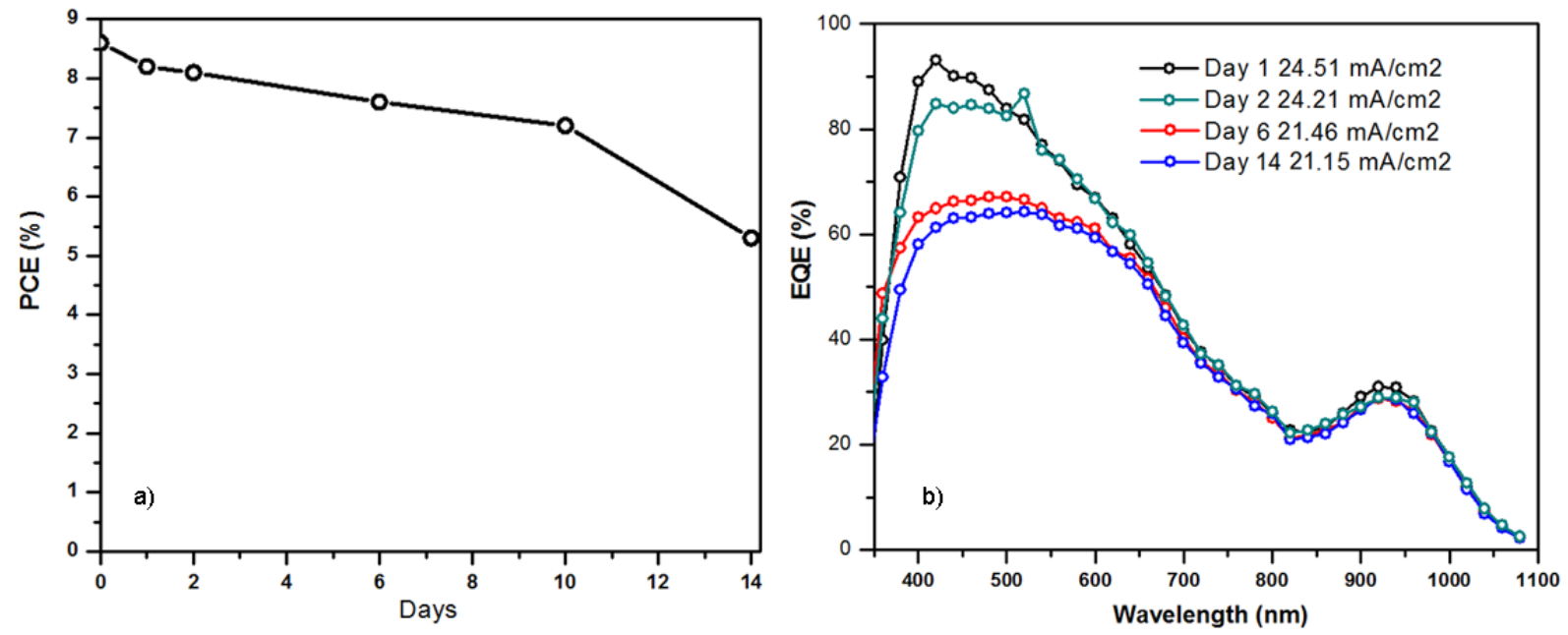

Figure S8. Device performance (a) and EQE curve (b) for devices with n-doped PCBM interfacial layer that stored in $\mathrm{N}_{2}$ glove box 
Table S3. Detailed parameters used in SCAP simulation

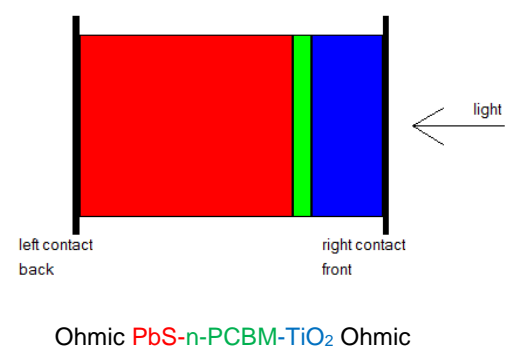

\begin{tabular}{|c|c|c|c|}
\hline & $\mathbf{P b S}$ & РСВМ & TiO2 \\
\hline Thickness (nm) & 300 & 25 & 100 \\
\hline bandgap (eV) & 1.1 & 2 & 3.2 \\
\hline electron affinity (eV) & 3.9 & 4 & 4.1 \\
\hline $\begin{array}{l}\text { dielectric } \\
\text { permittivity } \\
\text { (relative) }\end{array}$ & 20 & 2 & 66 \\
\hline $\begin{array}{l}\text { CB effective density } \\
\text { of states }\left(1 / \mathrm{cm}^{3}\right)\end{array}$ & $1 \mathrm{E}+19$ & $1 \mathrm{E}+19$ & $1 \mathrm{E}+19$ \\
\hline $\begin{array}{l}\text { VB effective density } \\
\text { of states }\left(1 / \mathrm{cm}^{3}\right)\end{array}$ & $1 \mathrm{E}+19$ & $1 \mathrm{E}+19$ & $1 \mathrm{E}+19$ \\
\hline $\begin{array}{l}\text { electron thermal } \\
\text { velocity }(\mathrm{cm} / \mathrm{s})\end{array}$ & $7 E+3$ & $7 E+3$ & $1 \mathrm{E}+7$ \\
\hline $\begin{array}{l}\text { hole thermal } \\
\text { velocity }(\mathrm{cm} / \mathrm{s})\end{array}$ & $7 \mathrm{E}+3$ & $7 \mathrm{E}+3$ & $1 \mathrm{E}+7$ \\
\hline $\begin{array}{l}\text { electron mobility } \\
\left(\mathrm{cm}^{2} / \mathrm{Vs}\right)\end{array}$ & $2 \mathrm{E}-2$ & 2E-2 & $5 \mathrm{E}-2$ \\
\hline $\begin{array}{l}\text { hole mobility } \\
\left(\mathrm{cm}^{2} / \mathrm{Vs}\right)\end{array}$ & $2 \mathrm{E}-2$ & $2 \mathrm{E}-2$ & $5 \mathrm{E}-2$ \\
\hline $\begin{array}{l}\text { shallow uniform } \\
\text { donor density ND } \\
(1 / \mathrm{cm} 3)\end{array}$ & $\mathbf{0}$ & $1 E 18$ & $1 E 18$ \\
\hline $\begin{array}{l}\text { shallow uniform } \\
\text { acceptor density NA } \\
\left(1 / \mathrm{cm}^{3}\right)\end{array}$ & $1 \mathrm{E16}$ & $\mathbf{0}$ & $\mathbf{0}$ \\
\hline $\begin{array}{l}\text { absorption } \\
\text { coefficient }(1 / \mathbf{c m})\end{array}$ & $\begin{array}{l}\text { See below (Figure } \\
\text { S6) }\end{array}$ & $1 E 4$ & $1 E 3$ \\
\hline $\begin{array}{l}\text { Radiative } \\
\text { recombination } \\
\text { coefficient }\left(\mathrm{cm}^{3} / \mathbf{s}\right)\end{array}$ & 5e-13 & - & - \\
\hline $\begin{array}{l}\text { Auger capture } \\
\text { coefficient }\left(\mathrm{cm}^{6} / \mathrm{s}\right)\end{array}$ & 1e-28 & - & - \\
\hline $\begin{array}{l}\text { Trap capture cross } \\
\text { section }\left(\mathrm{cm}^{2}\right)\end{array}$ & $1.2 \mathrm{E}-13$ & - & - \\
\hline $\begin{array}{l}\text { Trap depth relative } \\
\text { to } \mathrm{Ec}(\mathrm{eV})\end{array}$ & 0.25 & - & - \\
\hline Trap density & 1e16 & - & - \\
\hline
\end{tabular}




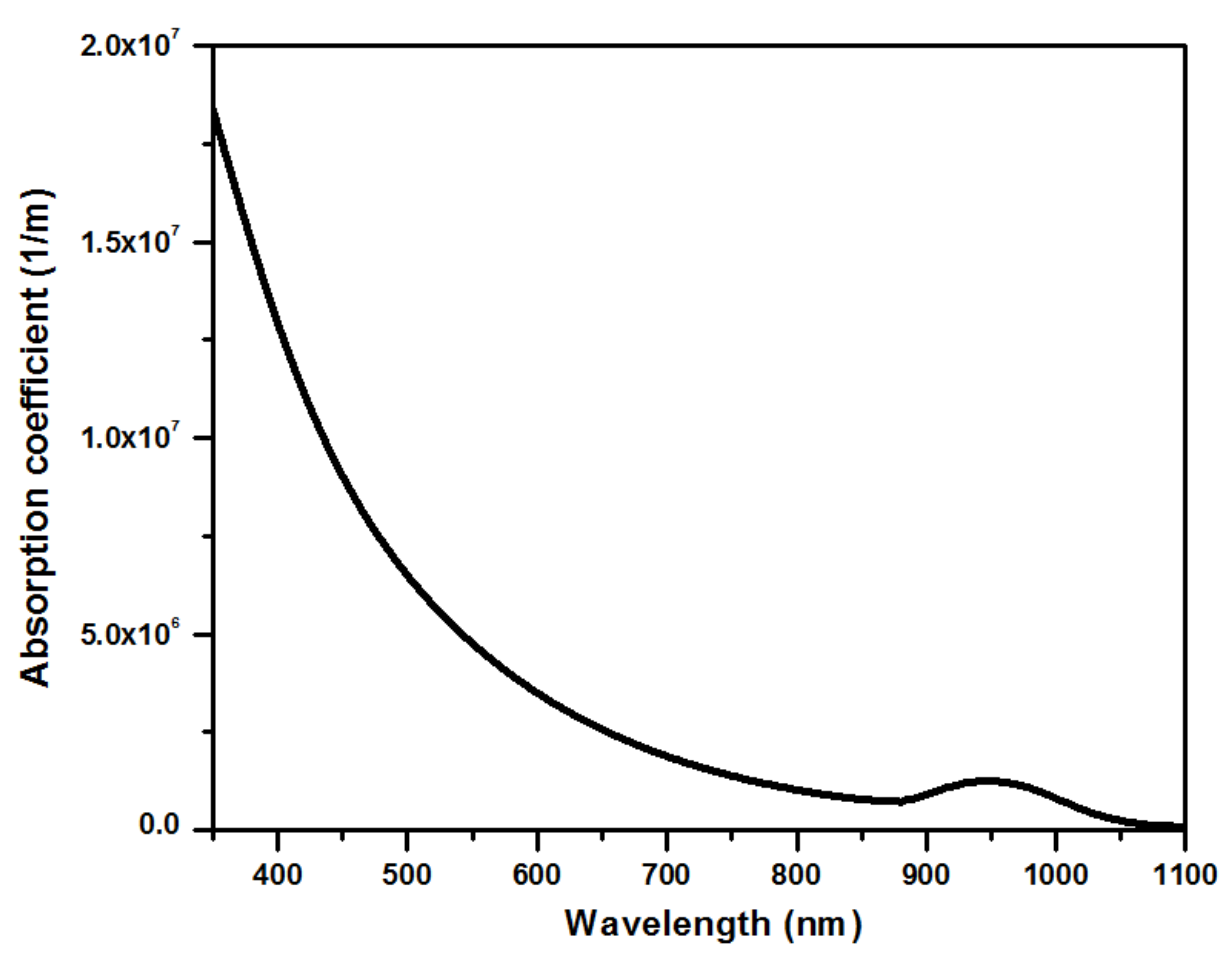

Figure S9. PbS CQDs absorption coefficient.

Reference:

[S1] K. W. Kemp, A. J. Labelle, S. M. Thon, A. H. Ip, I. J. Karmer, S. Hoogland, E. H. Sargent, Adv. Energy. Mater.2013, 3, 917.

[S2] R. Scheer, H. -W. Schock, In Chalcogenide Photovoltaics; Wiley-VCH, Weinheim, 2011; pp. 9-27; 